\title{
THE PLACE OF SKILLS IN LEGAL EDUCATION*
}

\section{Scope and Purpose of the Report.}

There is as yet little in the way of war or post-war "permanent" change in curriculum which is sufficiently advanced to warrant a survey of actual developments. Yet it may well be that the simpler curriculum which has been an effect of reduced staff will not be without its post-war effects. We believe that work with the simpler curriculum has made rather persuasive two conclusions: first, that the basic values we have been seeking by case-law instruction are produced about as well from a smaller, body of case-courses as from a larger body of them; and second, that even when classes are small and instruction insofar more individual, we still find difficulty in getting those basic values across, throughout the class, in terms of a resulting reliable and minimum professional competence. We urge serious attention to the widespread dissatisfaction which law teachers, individually and at large, have been experiencing and expressing in regard to their classes during these war - years. We do not believe that this dissatisfaction is adequately accounted for by any distraction of students' interest. We believe that it rests on the fact that we have been teaching classes which contain fewer "top" students. We do not believe that the " $\mathrm{C}$ " students are either getting materially less instruction-value or turning in materially poorer papers than in pre-war days. What we do believe is that until recently the gratifying performance of our best has floated like a curtain between our eyes and the unpleasant realization of what our "lower half" has not been getting from instruction. In the war classes this curtain is thin, scanty or absent, and we are brought face to face with the problem of making case-instruction more effective.

In your Committee's view this problem is basic to all discussion of curricular revision. In the Association discussion in Washington last year a most pertinent question was asked, and not answered: What is there that is good in the old methods? What did we get out of our own law study in the old style?

Your Committee are of opinion that that question is fundamental. They are of opinion that what we got, all of our passing students today

$\approx$ This is the body of the 1944 report of the Committee on Curriculum of the Association of American Law Schools. By arrangement it is printed here as well as in the Handbook in the hope that it may reach a wider audience among the practicing branch of the profession and elicit suggestion, criticism and aid in working out the problems discussed. Suggestions are invited. They should be addressed to the chairman, K. N. Llewellyn, Columbia University School of Law. Due to space limitations, the introductory summary has been omitted. 
ought to get, and can be made to get. They are of opinion that whatever else a lawyer needs, he needs as a minimum a reliable craftsmanship. Technique without ideals may, be a menace, but ideals without technique are a mess; and to turn ideals into effective vision, in matters of law, calls for passing those ideals through a hard-headed screen of effective legal technique.

Your Committee are therefore of opinion that the more "conservative" approach to law teaching which centers emphasis on case-law teaching of the traditional private law courses seeks values and has values which need careful canvass and which are indispensable to sound training for the law. These values we purpose to examine afresh. We purpose also to inquire afresh into our current performance in inculcating these values, to reexamine our going machinery of case-instruction. For a central problem is the problem of limited class-time and so of its most effective use.

Your Committee are not proposing to examine the whole question of the curriculum. We neither here affirm nor do we here deny the soundness of the claim that in modern conditions "half the curricular time should go into "public' law." We neither here affirm nor do we here deny the claim that "four ycars are needed, if the student is to be given adequate understanding of social background and law's relation to its purposes." We neither here affirm nor do we here deny any position with reference to the value of specialized training of any kind inside the law school. It is true that it is hard for us to see today how any curriculum can escape the meaning of the utterly pervasive impact of taxation, which today affects "other" "particular" areas of law as directly as does procedure. It is true that the problem of the administrative agency seems to us to be remaking the law and practice of many "fields" which once were rather comfortably "private" and relatively simple (e.g. mortgages, bank collections, contracts-with "termination" on one side, "collective bargaining" on the other, "forms" in the middle-etc.). But we are persuaded that no mere addition or substitution of subject-matter offers an answer to our needs. We are persuaded that there is no sovereign selection of mațerial which warrants urging. We are persuaded that every faculty will make its own decisions on the "public law" side, and that future curriculum committees will have to gather and report the results.

Above all, we are persuaded that all choices and changes must be faced in the light of certain hard facts. Those facts are that it is law teachers who will make any changes, and law teachers organized into law faculties. Such faculties have been trained in the old values and the 
old ways of instruction. They will insist, and in our opinion they will rightly insist, on not sacrificing the old values of our law instructon, in any change; nor will they depart lightly or far from their tested methods until they see effective substitute methods which can be put to use by our existing man-power. ${ }^{1}$ It is with this fact in view that we make our canvass. We examine the current methods of -case-instruction with an eye to making more explicit the values which inhere in them. We examine them with an eye to possible time-saving in communicating those values. Such conclusions as we draw, such recommendations as we make, presuppose the existing curricular structure. We do not, for instance, suggest any material rearrangement of any existing "First Year." That is a separate problem, not here under consideration. We take as substantially given the upper year "private law" curriculum. The little we have to say on "public law" has to do with possible methods of instruction, possible lines of selecting subject-matter, within any going curricular frame.

We do hope we may not be understood as "neglecting," "overlooking" or "disapproving" the matters we do not here develop. We face a single task, simple as compared with "curriculum" at large, but of itself complex enough. The task is that of making curricular room for movement, by getting our existing values inculcated more effectively, with less waste motion, with more sustained impact. Coincident with that are certain suggestions with regard to wise lines of widening our instruction, once room has been gained which may permit any widening. But the first task is to make curricular room by getting the present tasks done, on their ozen premises, in less curricular time. ${ }^{2}$ That task calls for some modification, but only for minor modification, of our current methods. Until that is accomplished discussion of new material faces a double handicap: first and on the point of "acceptance," it faces a "conservative bloc" within any faculty who have a sound professional uneasiness at taking on any new job until the old job has been done right; and second and on the point of performance, it faces the teaching job of getting "loose" material across, for ordered and competent professional use, to

1. Fortunately, Dean Langdell was more venturesome--D. F. Cavers.

2. "I sympathize warmly with this objective. But I do not think the task of achieving it calls, as the succeeding sentence in the text declares, 'only for minor modification, of our current methods.' Indeed, I think the present report demonstrates the contrary to be true. On the other hand, I believe-and my relation to the report is such that I can write without immodesty-that this report is a document of basic importance to those who would 'make room' in the curriculum. It points to a principle of organization which, as and if its implications are developed in planning and application, would end the domination of subject matter and lead ultimately to a far more efficient use of our limited time and resources."-D. F. Cavers. 
students whose minds are not yet ordered and whose professional level of skill is not yet competent. Our report seeks to be conservative in that it seeks means not only of conserving but of deepening and enriching the standard values of the traditional curriculum. It seeks to be progressive in that it seeks to open room for widening the curriculum on the "public" side. It seeks to be radical in that it seeks to get down to the roots of training for the law, and to work up from those roots.

\section{Production Engineering in Legal Education.}

Before the war effort American engineers were on the whole well satisfied with American methods of technological production. Those methods were deemed not only satisfactory, but the best in the worldmuch as is our case-instruction. Despite that, the war effort forced upon our engineers a recanvass of production methods from the ground up, - and the gains of two normal decades were gotten within two years. The first and most vital hindrance to a prior recanvass of this fundamental sort had been the fact that in any field of work a goal which is familiar and existing commonly channels men's minds into thinking bounded by the major familiar lines of method in which the men have grown up. But the war effort not only provided new pressure and incentive; by calling for production of new things, with new speed and effectiveness; it also forced recanvass of all methods: the traditional ways could not accomplish the new work. The engineers then discovered that the fresh new view of the whole production process which had been forced upon them developed startling new insights into how to get even rather familiar types of operation simplified, cheapened, speeded; into how to eliminate waste motion; into simplified design of product; into ability to make better, quicker use of man-power. The two key lines of thought were: (a) reanalysis and break-down of detailed processes, to find simpler and more effective ways of working out those detailed processes one by one; (b) a fresh view of the whole job, to reorganize all parts along more effective lines of coordination. These two key-lines of thinking fed each other. In combination they brought to bear the essence of all sound engineering, which is clean seeing of the goal and a testing of each intermediate goal or single operation on the basis not of whether it is familiar and "O.K.," but of whether it serves the goal as well as it can be made to.

Education is not technological engineering. The first major difference lies in the fact that human material refuses to be delivered at the educational "factory" in standardized or standardizable units; the second is that we have not yet developed testing devices for the product 
which can be applied either quickly or with an accuracy which would be satisfactory to an engineer. Yet the basic approaches of production engineering have their value in dealing with any job which man takes on: recanvass from time to time of the goal; reanalysis of intermediate goals and of specific operations in the light thereof; direct and simplified operation wherever possible and to the possible degree; a product which, whether uniform or not, has at least reliability in every unit plus a due margin of safety. Moreover, while "war education," whether within the services or beside them, has yielded no such results during the last few years as has technology, it has yet yielded enough to make clear that rethinking of goals and especially of methods of instruction can become startlingly effective. Instruction in the languages, for instance, has achieved hitherto unparalleled results. Instruction in the social sciences has by concentration on regions (as in some schools for administrators of occupied territories) again achieved results which had before been only dreams. There are of course dangers in any material change in educational method. The, familiar is at least that which existing personnel have already proved their competence to handle, and which experience has also proved to have some real value. That counsels caution and care. What it does not counsel is standing pat without inquiry and experiment.

For perhaps the most striking fact about legal education during these past thirty-five years is that while effort after effort has gone into the problem of what bodies of law to teach and how to organize them for teaching, the dominant methods of actual teaching have remained in the area of undiscussed tradition rather than of ongoing restudy. Worry and experiment about teaching method have remained largely individual, and the individual worry and experiment has remained, even when superbly successful, with no impact outside the given faculty (to most, unknown), and with impact even within a faculty, in the main, merely in terms of permission to one man to be different. If pride is taken in his course (as sometimes) the pride has been circumscribed strictly within the two, three or five semester-hours of his course. His colleagues have still not meditated often on the meaning of his experiment for thirty or forty other semester-hours.

We have indeed a long and honorable group-tradition on how to make and how to handle case-books, a tradition with a multitude of variants and changes, each man learning from the work of his brethren, each man's work being also tested by his brethren. ${ }^{3}$ But we have no

3. Compare Ehrenzweig's excellent and cautious general review, The American Casebook: "Cases and Materials" (1944) 32 GEO. I. J. 224, where much of the literature on legal education is also conveniently gathered. 
such cumulated, shared, group experience in regard to any other type of teaching method, nor yet in regard to the detailed procedures of caseinstruction in class.

This makes a compelling case for inquiry. The prospective return of men now in the service, to enter or reenter for training to practice in a post-war world, makes the compulsion immediate.

\section{Values of "The" Case-Method.}

Our now traditional method of instruction consists of practically three years of "case-method" teaching, organized in terms of courses each in a "field of law," everywhere supplemented indeed by some other types of instruction but always by other types which remain both minor and subsidiary. The supplement may be provided course by course, as when the "materials" in the book provide historical text, or problems, or informational notes; or where the instructor lectures on a topic not fully "covered" in class, or sums up on a topic which has been "covered"; or where we "always raise" this or that as we go by. The supplement may be provided by separate courses, as in office practice, supervised moot court, practice court, introductory material, lectures on jurisprudence, legal ethics, or some other off-standard "field." Supplement may be provided for all, or as with free-style seminar instruction for a small group who elect it, or as with law review work for a few selected from the top. Always, it is merely a supplement. The case-class is bone and meat of our instruction for the generality of our graduates.

A first problem and a serious one in any reappraisal of results is that "the" case-method presents itself in life as a hundred and more different methods which need to have in common little more than the presence in class of a case-book. At the one extreme, now (happily) almost dead, is the pure lecture which uses the cases in the book merely as illustrations; at the other is the rare but occasional "teaching of the whole course out of one case" by a majestic and systematic series of hypo. theticals. In between is any instructor's individual variant, reached by trial and error, conscious experiment, accident, or temperament, on the basis of the net impact on him of the fourteen varieties of case-method he met while a student and of all the case-books he has made or used.

Nevertheless, there is enough similarity among case-classes to allow of certain generalizations concerning their educational effect when used in the now current fashions and as the dominant method of our legal education; and there are certain other generalizations which are highly probable in regard to what could be accomplished by rather minor changes in present methods of case-class work. 
Some of the things which it seems safe to state are these:

Case-instruction is not only the most significant American contribution to legal education, but it is unrivalled as a machinery for basic training in analysis of holdings and in application of doctrine. It is amazingly flexible. It can be readily adjusted to almost any size of. class and almost any instructor's individuality. It is certainly a necessary part of future American legal education.

It is an almost unique machinery to aid an instructor of average gifts to both organize his instruction and hold the attention and interest of his class. This virtue begins to fade, at present, by the second semester. On the attention and interest side the virtue is at present almost absent by the fifth or sixth semester. There it now takes instructor's skill, variation and addition, or else peculiarly interesting material, to make case-instruction go over to satisfaction; it ceases to be the method which carries the instructor and becomes instead a question of the instructor carrying the method.

It is to be strongly suspected or even to be taken as a fact that in the upper semesters the best students have absorbed the benefits indirectly communicated by case-instruction and are ready to go after other and further training, while the less successful, still baffled by the method, are becoming discouraged; only a minority somewhere in the middle is "taking hold" and finding satisfaction.

On the basis of our current case-instruction the upper range of student develops rapidly a whole series of somewhat intangible but magnificent by-products in the form of legal skills which appear to flow not from the subject-matter of any course or courses nor yet from any particular instructor, but rather from a period of exposure to "the" method in different varieties. The satisfactory growth of these by-products (summed up variously as "legal thinking", "legal method", etc.) is definitely correlated to the sharpness of analysis and cleanness of thinking prevalent in a faculty as a whole. The results are visible in law review work wbich (whether supervised or student-run) demonstrates undergraduate ability in the top brackets not only to analyze, but to investigate, not only to investigate but to do small-scale critieal synthesis, and not only that but also to organize composition on a moderately effective level. ${ }^{4}$ Moreover, even a supervised law review includes a sufficient

4. "This ascribes to case instruction results which I believe are attributable in much greater measure to the training which the law review work itself provides."D. F. Cavers.

"Among the chief elements which law review training adds to case instruction are: concentration on a particular problem; attempt at complete coverage; independent research; writing with careful stress of accurate thought and statement, and within a somewhat clear tradition; consultation, revision and reworking 
quantum of revision and training by the student editorial staff to demonstrate the virtues of case-training in producing a material degree of communicability and transmissibility of its very by-products. But it is striking that this is thus demonstrated only for the best students, and demonstrated only by way of a machinery which lies outside of the case-classand which has all the earmarks of apprenticeship training.

We are not as a profession much agreed on exactly what the byproducts of case-instruction are. We are, however, agreed that they fail to reach everything that we know students need to learn. For instance, we recognize "use of the library" as needing special teaching; indeed one price of case-instruction' is some vicious encouragement of the "one-book" habit. We are fairly sure, however, that the by-products properly include the ability to analyze a case doctrinally down to its "exact" or narrow (i.e., undistinguishable) holding. Practice then differs hugely on how far skill is also developed in extracting and using "the principle of a case"; and there is good reason to believe that few faculties are equally effective in developing in their students each of these two always alternative doctrinal techniques. Similarly, caseinstruction has proved its ability to impart to the better student either a strong feeling for the effect, pressure, guidance, often control, given by past doctrine as currently phrased, or else a strong feeling for the effect of the court's sense of justice, fairness, wisdom in the situation; but there is good reason to believe that few faculties are effectively developing either one of these except at some real danger of underdeveloping the other. Yet it is hardly arguable that the student needs not only both, but a good working understanding of their interaction.

There seems also to be little question that three years of current case-instruction develops in the upper student brackets an adequate positive knowledge of many of our major traditional legal categories and also a less tangible something: a basis on which later experience rather rapidly builds a moderately workable approach to a court's probabie classification of a case. This is commonly spoken of as "sound theory", and it is vital.

We call attention to the fact that in order to make safe and accurate most of the foregoing statements of virtues of current case-instruction we have been forced to limit them largely to "the upper brackets of student". . The same would hold if one were to further explore

under an apprenticeship type of supervision. The stepping up of instructional power by such a combination cannot, on the premises of this report, be challenged. But I think Mr. Cavers understresses what the good law review candidate brings from his prior case-instruction, as I think McDougal and Lasswell overstress it." K. N. L. 
such other and indubitable by-products (for some) of case-instruction as "testing of an alleged rule by hypotheticals and rephrasing it into nicer accuracy" and the like; or "defending a position"; or "straight, consistent thinking"; or "accurate use of words"; or "accurate reading".

We do not believe that any case-instructor can face the "lower half" of his semi-annual set of blue books, up even through the sixth semester, without recognizing that current case-instruction is somehow failing to do the job of producing reliable professional competence on the by-product side in half or more of our end-product, our graduates. This is not a question of novel objectives, it is a question only of how far and to how many the standard method is getting across in reliable fashion the virtues which properly inhere in the method itself. They inhere in esse, as to the upper brackets of student. They inhere, we believe, in posse, as to our whole range of graduates.

\section{Current Difficulties in Case-Method.}

We believe that current case-instruction has slowiy come to slide away from one of the major virtues of earlier case-instruction, and that it can be revitalized by recapture of that virtue. The virtue in question is simplicity of the thread of the teaching, along with which went originally a training in a very few by-product skills at a time, which was a sufficiently sustained training to get such skills really mastered by all who passed the course. We do not suggest recurring to the detailed practice or material of any of the great teachers of a day now gone; what we do suggest is that it is vital to any curriculum based in any part on case-instruction that its desired and expected by-products be more closely analyzed for study and that these by-products be dealt with not indiscriminately and therefore without sustained impact of any one of them on the more puzzled students, but in planned and systematic concentration until each by-product is really put across throughout the class as a reliable and habitual working skill. We are convinced that the recurrent sets of bluebooks show that unplanned, "automatic" results in the vital by-product skills have ceased to occur with this kind of reliable regularity over the whole of a class.

The older case-teaching of the '80's and '90's had a number of pedagogical advantages in its job of carrying "legal method" and the like down into and reliably throughout the student body. Field by field -that is, teaching unit by teaching unit-the rules of law had branched less far, less intricately, than they have today, unless: perhaps in a few phases of property. Arbitrary or obsolescent feudal complexities had dwindled; arbitrary or emergent industrial complexities were only in 
bud. "The" "subject-matter of the course" called for a lesser proportion of the students' labor and attention, leaving more energy and a less obstructed eye free for the "indirect" learning of "legal techniques". For similar reasons, though in wholly dissimilar fashion, the fact-side of the cases gave pure aid in those days, where it now gives quite as much hindrance as it does aid, to sharpening the inculcation of the by-products. The juice of "case-method" is indeed the concrete situation; but the inexpert student in class can milk the most concrete situation only when even an inexpert can understand it on its fact side, can really get into it, feeling and judging somewhat as the hypothetical court can be expected to feel and judge about what result on doctrine and on sense is a satisfactory result, what result is dubious, what result is absurd. Only so can the class work intelligently over the question of what is fair or wise, obviously right or obviously wrong, so as to check an overgeneralization or expand an undergeneralization or shift the direction of a generalization in favor of some cleaner or wiser criterion. The situations of the '80's and '90's were so much closer to a student's prior experience or to his quick appreciation than are those of today that this virtue has been seriously. undercut. It is doubly undercut when modern editors shorten the facts, omit counsel's argument, and chop out of the opinion all those "extraneous" points which were busy and will continue to be busy flavoring the case for actual parties, actual counsel and any actual tribunal. The same virtue is undercut from the other end if complex fact-situations are presented in such rapid sequence as to cause mental indigestion or slipshod reading. Since in the present state of law and fact we of course cannot recapture the relative simplicity of subject-matter which prevailed half a century ago, our inculcation of by-product values is hampered, our emphasis upon them is interrupted by the pressures of the subject-matter. What once resulted "automatically" no longer does so, save among the better students. We are therefore forced toward a more conscious study, a more careful organization, for carrying throughout the class the same essential by-product values which once came quite indirectly from the mere handling of course after course in case-fashion.

Two points of mode or fashion further complicate the pedagogical problem. For one, we have now for decades been adding topics to the earlier case-books faster than we have been dropping topics out; and more "subject matter" material in the same classtime means less time spent on, less sustained training in, "method". For the other, it was once the doctrinal mode to reduce each field of law to a severely limited number of fixed and (for classroom purposes) unchallengeable principles. Such principles were the organizing structure not only of "the law 
of the field" but also of the case-book; and too little attention has been paid to the degree to which explicit subheads became dispensable in the older case-books precisely because such principles, implicit in the book, became explicit early in the class-discussion. These same principles became furthermore the bases for determining all policy questions: they were few, they were sharply phrased, they were (for classroom purposes, at least) final and compelling. Their continued use, even though general propositions do not in fact decide the more puzzling of concrete cases, provided nevertheless a constant training in thinking and in argument from familiar premises, from solid and phrased premises, from professionally accepted premises; and if the reasoning was often largely verbalistic and even blind, it was nevertheless a technical and sharp training in a basic professional skill-an indirect product of case-instruction. As against this, the modern emphasis in regard to policy runs to the court's problem in shaping or reshaping the law, it runs to the court's quest for justice and wisdom. So far from offering practice in the use of fixed premises, it complicates the class-room scene by opening up an endless series of situations in flux or in doubt. Although this shift in emphasis is easy to overdo, it is a sound shift, and it is with us to stay; but its meaning for pedagogical method is that we need today some means to recapture the sustained, repetitive training in legal skills ("legal method", "legal thinking") which once really trained a whole class as an "automatic" by-product of case-instruction.

One can sum up the situation thus: case-instruction is today threatened with slow suffocation under a constant accession of new and more complex materials and new and more complex demands which are made upon all case-courses at once and indiscriminately, and of which materials and demands only a severely limited number can be handled effectively and down through a whole class in the time allotted to any particular case-course. The older relative simplicity of the structure of "subject-matter" on which case-instruction was built (or, more accurately, hung) allowed an unplanned indirect instruction in the vital byproducts to work out in sufficient repetition and with sufficient sharpness to penetrate an entire class. The modern complexity of material is accompanied also by an increase in the range and type of problem canvassed in our classes: dabs of legal history, of jurisprudence, large chunks of the problems of judicial policy, problems of counselling suggested by the instructor's experience or the annotations of the case-book, materials of economic or social or political background-all these come in, but they come in helter-skelter: "The place for that is not a separate course; it ought to be a part of every course !" So we say, and so we 
keep adding. We do our best, but the bluebooks up through B- and often beyond proceed to show imprecision, inadequacy, unreliability in those by-products whose successful inculcation was once the case-system's pride, to say nothing of those other and more complex by-products which we have more recently come to recognize and value. The better men still get the older vital by-products by indirection and get them well. and they do so inside of three semesters. The best get not only that, but get also many of the vital additional values sought by modern legal education; often, to be sure, only when law review work is also fed into their training. But the lower half still fumble, even in the third year, on elementary "legal thinking", on elementary "legal method". Third year " $C$ " books are not professionally competent.

This has peculiarly distressing consequences as we face the increasing pressure of material on time in the upper years. Our upper-year pack-pace is slowed by those men whose first-year work has failed to give them clean command of elementary skills. This slowing of the pack-pace comes in an epoch when the curriculum is desperately pressed for time.

\section{Case-taw Skills as an Explicit Focus of Case-Instruction.}

To sum up, since the skills imparted by effective case-instruction are vital not only to law-practice but no less to all upper-class legal education, the first question becomes one of recapturing the old-time reliable effectiveness in imparting those skills, and then of capturing for any other skills we seek to impart the same old-time effectiveness of inculcation.

The lesson from modern production analysis is that machinery designed to do many things at once or indiscriminately can commonly be made more effective if the needed operations are broken down and tackled one by one. The lesson from general pedagogy is that to master a skill the less gifted student must have sustained practice in that skill; not only practice, but repetitive uninterrupted practice on that particular skill, until it is a part of him. Another lesson from pedagogy is that it helps a learner much if he is told what he is supposed to do so as to guide his efforts; and that it helps him if the cumulative things which he learns by practicing them one by one are written down in sequence (in "slogan") and in orderly arrangement (in syllabus) so that he may have at hand a reminder of what has gone before and a picture of what it all comes to and of how one piece of it fits with another and with the whole. The lesson from the case-system of the classic days is that clear guiding threads, simple, explicit, and few, tremendously help case-in- 
struction to infiltrate its values, reliably, to every student who should pass a course. The lesson from our bluebooks is that with regard to half or more of our graduates those indirect values which everyone of us recognizes as the major value to him of his own law school days are no longer being communicated throughout our classes in craftsmanlike adequacy; and that we must take steps.

Our common defense against, fully realizing this uncomfortable fact has been to remind ourselves that brains are unevenly distributed, "that there will always be C and C-men", or even "that the reputation of a school rests on its best". We suggest that such lines of thought offer no proper defense. We urge that the reputation of Harvard was not and could not have been built in the days of the classic "embattled" casesystem by any few best men, but only on the reliable competence in professional case-law skills of its whole body of graduates (without which their deeper training in theory would have been worthless), even when they were slower minded or less imaginative or of the routineer type, and so barely passed. We urge that a school which trains for the bar carries responsibility for every graduate. We urge that the breaking-in of students to law review work, centered on case-craftsmanship, shows simply amazing results in the rise in the level of that craftsmanship within a one-semester training period. Finally we urge that accident, personal contact, small group instruction, teaching experiment, readmission, observation of tutoring, moot court or essay work done at students' leisure and the like, has over the years brought under every open-eyed teacher's notice a whole series of "hopeless C-men" who have blossomed into good craftsmen, once they found out what it was all about and once they had their own chance to work out and practice the required case-law skills. The same conclusion is forced upon us by those graduates who turn into craftsmen only after they leave us-as to whom there is little reason for pride that we have left the job to be done at their early clients' cost and risk. In a word, the indications are not only that the human material is capable of doing vastly better than our "lower" bluebooks show, but that means are available, without material disruption of existing first year curricular arrangements, for developing some good part of these latent possibilities. The responsibility is so great that we must wrestle with any live possibility. The war production situation shows that traditional ways do well to be recanvassed against their purposes even when they have seemed to be "obviously" the best available ways.

One road which would hold promise we here merely mention without discussion, because it seems doubtful that our profession will soon be content to depart greatly from the tradition of "a course in" any 
"subject". That road lies over really intensive class-development of one small portion of "the field" as marked out by case-book tradition, leaving all the rest to independent reading, with guide-lectures and perhaps question-periods, and with a careful syllabus. Such intensive treatment could profitably focus either along lines of legal topic and concept or along lines of factual situation, or both, until the grasp achieved would become that not of a student but of a lawyer, and the material would open for creative but supervised application to problems of practice (this last being what law review work commonly stops short of). For such work the returning "farmed out" instructor would be peculiarly adapted; and he could urge in favor of it that our expected or standard content of "a course" in any field has elements of the arbitrary and artificial, as do the boundaries of our "fields" and our curricular selections from among the important topics of our law. But our traditional coursetitles, the traditional topics within each, and the editor's labor in gathering material into a readily accessible book make us sufficiently uncomfortable over what we may fail to "cover" to render intensive class-development on any large scale unlikely at this immediate stage of our development. ${ }^{5}$

What can be done, however, and done without material interference with our accustomed apportionments of "subject-matter", is to make explicit the range of what used to be by-product instruction, to get clear to ourselves and our students what these case-law skills are which we propose to develop in them, and then to allocate to each first-year instructor the job of accomplishing in his particular course-whatever else he does-an adequately sustained training in the particular case-skills for which he is made peculiarly responsible.

One runs at this point into a surface-difficulty, but it is not a real one. As is the case with most values which rest in presupposed and largely unspoken tradition, there is no general agreement on just what those by-product values are which case-instruction is to impart. There is no doubt anywhere that they are essential values, even the most essential ones. Yet it would not be easy to find two men or two faculties agreeing on any detailed list of what they consist of. But general agreement is not necessary. What is certain is that it will pay any man or any faculty to try to set down explicitly what specific types of skill he conceives the method should inculcate (a) as a basic minimum for every student; (b) as a desirable additional result, wherever possible. 'Any

5. My personal view remains that at least after the first year "coverage" of "the law" is more wisely sought by syllabus, by the printed lecture-printed, as delivered, for student's reading - and by selected other reading; and that class-work pays by far the highest return when it is intensive.-K. N. L. . 
thinking on the subject reveals rapidly that the number of more or less clearly identifiable skills which we all have vaguely in mind is rather large, so large that apportionment of particular ones as the certain responsibility of any particular instructor (whatever else he may do) is easy; so large that a fumbling student would be greatly helped by the explicit statement of which of them is in question at any time; so large moreover that as each of us hops today from exercise in one of them to exercise in another and a third and a fourth and unpredictably across or back again it is no wonder that all but the better of our "victims" remain confused.

At the close of the last war Wigmore prepared a "job-analysis" of legal skills which has real value. Though it was too complex for effective general use, it offers a fine starter for any teacher's thought. Columbia is now at work on materials and a syllabus for a course introductory to law study with peculiar concentration on the accepted methods of extracting doctrine from cases. The course is intended to be taught from cases, especially cases used in other courses, and to have the teaching concentrated in the earlier weeks of the opening semester. It should go far to render one piece of the indirect values of the older case-instruction both explicit and organized for sustained work, and then for sustained reference back in other courses. Yet the problem of conscious allocation of training-effort, allocation by instructor and by course, will remain. It will remain, first, because it is not enough to know what a skill is and to experience it or try your mind at it once or six times; it must be drilled and practiced until it becomes a part of the learner, as clean tackling, accurate falling on the ball and those much more difficult skills of following the ball and following the play become part of a football player. And the problem of allocation will remain, second, because the needed skills are too many and too varied to be thus learned all in one course, or to be really learned by the non-elect by way of happenstance, non-sustained "practice" spattered over any or many ${ }^{\circ}$ courses.

It is fairly obvious, for instance, that there are at least three strikingly different levels on which "the". "simple" problem of the doctrine of a case or of a body of cases can be discussed. There is first and centrally the judicial level: what is the right or best reading? That is our traditional main class room approach, as derived from Ames, modified and complicated often, these days, by distinguishing sharply what the courts (or a particular one of them) are likely to hold from what the instructor thinks they ought to hold. The second approach is on the advocate's level: what reading will the case or cases bear, in terms of our correct doctrinal techniques, and can that rcading be made not merely 
colorable but really persuasive (to a particular tribunal)? This or something much like it used to make up one large phase of Langdell's case-method, with its strong emphasis on the arguments actually made by counsel or on those which could be made, for plaintiff and then for defendant. This advocate's approach is a vital addition to the judicial or law professor's level of discussion. It is worth separate study' and drill. It is the use of cases in defense of a position. To carry such advocate's use of cases and of doctrinal techniques through one whole second-semester course, with the judicial level there treated chiefly as the factor which limits and guides advocacy, as being the level to which advocacy must appeal and on which persuasion must prove effective, that would make any student both see and retain the difference: not a mere doubling, but a raising to second power of his professional competence in "case-law skills". But to reach down through the class and penetrate, such specialized advocate's use of doctrinal technique must be repeated in some particular instructor's demands and in the students' consequent exercises until it becomes an habitual skill, always distinguished from because always limited by the problem of diagnosing courts' feeling for what doctrine, on the cases and the facts, should and will appeal as the sound doctrine. No such introductory course as that projected at Columbia, no such job-analysis as that of Wigmore, can substitute for this type of sustained training on the advocate's level. No unreckonable shifting from the judicial level to the advocate's and back again can get either of them clear to the less gifted student. Note in the older days when phrased principles (basic at least for the class) set not only $a$ but the major foundation for all argument of both policy and "law", how much closer training in a judge's "sound" solution came to coinciding with training in an advocate's "legal defense of a position". Note today, with policy made a separate question, and with the courts "taught" as seeking the wise choice within their field of action as that field is limited, and narrowly limited, by doctrine, how much more sharply the advocate's level of discussion differs from that of the court, in school as it does in the living practice. When Cardozo spoke of most appeals as foredoomed in their outcome, he spoke from the standpoint of one working on the judicial level. He spoke also from the standpoint of a judge faced with a succession of appeals by lawyers who had not learned in school that the cases offer many doctrinal possibilities on the advocate's level, but that it is the court's job to read as the sole correct possibility some one of the technical possibilities which makes for sense and justice.

Again, the same case or cases will open a wholly different level of 
discussion if the office-counsellor's approach is taken. The vast vaguish borderland that surrounds the law of consideration (for instance "promissory estoppel") has little business to trouble the office-counsellor at all in his shaping of actual transactions, except as an indication of what to keep away from. His business is on the one hand to avoid any suggestion of such a thing as promissory estoppel, on the other to produce in every case a bargain unmistakable in form, then to put in enough of substance and enough of fairness to leave no room for controversy, and finally to make his written record too clear for doubt. In the field of conditions he has a different but similar problem. Wherever there is settled law which is also going to stay settled, that is the law he is looking for: safe bedrock-law to build on, with, and within. And if there is not enough of such bedrock-law to hold his needed structure or to base his needed course of action, then his judgment of cases or statutes or judicial attitude runs in terms of the degree of safety of a reading of doctrine, including the possibility that the actual test-case may come into the hands of an incompetent and get botched. His mind moves into how to shape action and transaction more than into how to shape and argue a formulation of doctrine. Surely this way of handling cases and doctrinal techniques is also as much a proper by-product of modern caseinstruction as ever was "legal method" applied to a border-line hypothetical teaser of theory. But no introductory course can provide it, because practice in it roots in deep and intimate knowledge of a particular concrete background of fact and need. Yet, first, consistent discrimination among competing case-law formulations in terms of "safe, pretty safe, not safe.enough", is as much a needed lawyer's skill to be made habitual as is discrimination in terms of "sound, probably sound, dubiously sound, unsound", or in terms of "technically tenable or untenable; and if tenable, then compelling, adequately persuasive, risky, or too risky"; and only sustained work in some caurse or courses can make the counsellor's peculiar skill of approach either stand out for separate observation or become habitual. Second, thinking about rules and cases in terms of what you can do for a client in view of those rules and cases is again a vital professional habit and professional skill to be acquired. Third, if ever a system of instruction was built to offer material for such thinking and such training, it is instruction by way of concrete cases.

The foregoing is enough to indicate the range of case-law skills in which instruction is needed and to indicate that it is a greater range, a range with more subtle distinctions, than was the case in the classic 
days. ${ }^{6}$ Oir job on the side of the skills alone is bigger than was that of our case-instruction forefathers, and calls for more time as well as for more careful organization. Now, as then, at whatever cost in range of "subject matter" covered niay require to be paid.

Indeed there is no escape from one proposition: a first year course which takes on as a deliberate part of its job and adequate training in one or more particular skills must, to get that job done, reduce its "content" of "subject matter" for standard classroom coverage by at least a third. To merely add a new job to the old is to further threaten both.

We make no effort here to further explore the range of by-products of legal method, technique or thinking which case-instruction should give off. We are clear that those on which any faculty can agree are many, and that they need analysis and specific statenient. We believe that such statement can wisely go into detailed syllabus form to guide students, to give a basis for apportioning the training, to give common reference points to the team of instructors in the first year and after, and to remind students throughout their law study of what techniques they are supposed to be studying or to have become familiar with. No such syllabus bars individual variations. There will for instance always be the instructor who teaches that the clear principle outweighs the specific, unsound holding, and the other instructor who teaches that no principle is clear when the holding runs the other way. The student needs to meet both views in school. He will, in court.

Moreover, as stated, whatever by-product values a given faculty

6. "The number of rather distinct case-law skills which an instructor las at his finger-tips is amazingly large. The number of them which a beginner can effectively practice at one time is amazingly small. And he is much aided if the skill or skills which are to be the main focus of a given day's or week's work are indicated in advance. The accidents of the discussion tend to throw most instruction unpredictably into hammering now one, now another of such skills, against a general background of demand that all of them be more or less on tap. Thus on Monday an instructor will be consciously pounding home the need for spotting the precise procedural issue, the difference between the question raised by demurrer to the plea and that raised by challenge to an instruction, and the like. The class comes in on Tuesday all set for this, only to find that a literal repetition of the court's language in the first case forces the instructor into testing the announced rules against a series of hypotheticals, the emphasis shifting in consequence wholly onto accuracy of substance-in-statement, and wholly off of the inescapable quantum of anthority of the holdings. Tuesday night the class has no idea of which to center on for Wednesday. The give-and-take of class discussion requires such elasticity of actual treatment; but it has no business to distract the student from repetitive work on and with the focal skill of the moment. And it is plain that if the particular skills which are to have attention are listed, and allocated for special attention to groups of cases well fitted for practice on and in them, that the student can thereby be materially aided in his preparation and careful practice of one thing at a time as the central thing (the others being drawn in as needed). Such a listing moreover offers a vitally useful body of later (or of forward) reference, to ease the integration of skills previously studied (and almost learned) with the one which is under practice at any time."-K. N. L. 
may deem essential, we are convinced that the current shotgun scatter of case-instruction in every phase but that of "subject-matter" has today removed desired values from the category of $b y$-products produced "aurtomatically" and reliably, except with the upper range of student. The desired values, one by one or two by two, must under present conditions be made into products consciously sought, at the expense of substantive coverage and by concentration upon one or a few skills at a time for a month or for two months or for a full course until the desired skill-values are really mastered by all. Only so will the old and the new true virtues of case-instruction again pervade the work of every graduate, and only so will case-instruction again offer a reliable foundation for upper-year work.

We also believe it to have been demonstrated by the work of Fuchs, Wechsler, and Weihofen in handling examinations for governmental legal service that devices have been developed and can be further developed for testing the case-law legal skills as such, and in material independence of the student's accurate remembrance of doctrine. The necessary specific information or cases to be dealt with in any such testing can be provided along with the examination itself. And it seems to us that few suggestions could be more serviceable than this: that so far as any conscious instruction is devoted to the legal skills proper to flow from case-teaching, the acquisition of the skills concerned in any course should be thus tested separately, course by course, uncomplicated by and unmixed with any other testing which may be needed either in the "content" of the course or in the student's general ability to handle "legal problems" mixed in the usual fashion of knowledge and of general skill in analysis and organization of answer. The gains by such separate testing are two, and each is great. First, it gives much sharper information on where further drilling or sharpened method may be needed: Second, it directs the student's attention to the fact that method is as much a part of "the course" and of his education as is "the law". It is precisely the lower range of students who need to have that made clearas also to be shown wherein these points of method lie.

We remind that we are concerned with a canvass of possible curricular improvements which combine three features: First, they are designed to save curricular time in accomplishing our standard objectives, and thereby to open the road for dealing with other objectives. Second, they are designed to involve no important disruption of the existing curricular structure. Such structure we conceive to be the responsibility of each particular faculty. ${ }^{7}$ While survey and report of the various cur-

7. We do not suggest that the Association has no function of leadership. We are addressing ourselves only to the immediate task in hand. 
ricula or of particular innovations is valuable and should be made as changes may appear, this report is directed to preparation for post-war by seeking to utilize for legal education the stimulus from general war experience. We find that stimulus centering on the recanvass of ways and means, of "production" methods, and on the retesting of intermediate objectives. But we also find one of the lessons of the war to be the importance of utilizing the existing institutional structures and the existing "know-how" of personnel. This last leads to the third feature of all improvements suggested: they call for no skills or "know-how" which are not already on tap, in bulk, in our profession. We do not here suggest whether other improvements may or may not be desirable or needed which might call for wholly new materials or teaching methods, or for new man-power. Any such possible change is simply outside the scope of this report.

\section{Certain Legal Skills Other Than Case-Law Skills.}

What has been said above in regard to counselling and advocacy suggests a number of other inquiries. Despite its current character of standard tradition, as if it had always been, it pays to recall that as law .and training for it go the system of case-instruction is a rather recent invention, short in experience. It would be amazing if so young a development should prove complete and final or even satisfactory without important alteration and supplement. No other product of our law has managed to do without both of these.

In particular the question presses whether there were not virtues in apprenticeship training which need recapture and which can be recaptured even in the classroom. It is striking that other professions devote much schooling time to one or another form of the applied arts which the student is expected later to practice. Apart from the clinical work and interneship of the medic, apart from the practical summers or years of the engineer, we find the theologian receiving instruction not only in his doctrine but in how to build sermons, how to handle parish problems, and the like; we find schools of business administration focussed on not only learning principles but solving problems of practical conduct of enterprises; we find the treatises from which the medics study packed with advice on what to do in practice. And whatever the deficiencies of the older apprenticeship instruction in law, it did have this value of bringing instruction in the craft-skills, in how to do legal jobs well and wisely. It still has that value, as any lawyer can testify who ever was broken in under a good senior.

One of the major gains which may be hoped from the huge "farm- 
ing out" of law instructors to government and to private practice which the war forced on us is the return to the schools of a whole body of teachers who have become sharply aware (1) that it is not enough to teach "the law", even plus the "by-product" values of case-instruction; (2) that they have tested out their own competence in the craft-skills of practicing the law; and (3) that what they have learned is in material part capable of being brought into so communicable and teachable a form that it can be and should be taught in school. ${ }^{8}$ One of the major needs of our profession today is the mobilization of the fresh knowledge, insight and energy of this kindled and tested man-power, to widen the base of our subject-matter and methods of instruction, to expand our goals, to fructify our curricular performance. The best time is while experience and enthusiasm are fresh, and while the pressure of the returning service men is on us. The service men will ask, and ask as of right, a better and more effective instruction to weigh up in part their sacrifice of years.

We remind that the insight and the man-power are as against prewar conditions largely new insight and new man-power. Where, before, practice has been practice and teaching has been teaching, here we have trained and experienced teachers who have gone into their practice and gone through it with teachers' eyes and teachers' understanding of how the experience in practice can be organized for teaching. Such men see differently, while in practice. What such men bring back is not mere experience and competence in practice, but teachable experience and competence. This in the law-teaching world is a new asset of knowledge and know-how, arising at a time of peculiar need.

In seeking to find means to meet the demand of the returning service men your committee have been forced to challenge one prevailing baseline on which the present standard curriculum is built. The matter goes not to inherent structure, but to emphasis. The challenge is to the sufficiency of our current organization as built primarily in terms of the substantive law of various fields. The existing dominance of organiza-

8. "I wish that I shared the awareness reported under point (3) with onehalf the sharpness with which I recognize point (1). My own experience, and I believe it not atypical of law teachers who have served on the legal staffs of war agencies, has not yielded learning which can readily be brought into communicable form. Given the time and the perspective which withdrawal from work on an emergency basis will afford, I think we shall discover that our views of law have been deeply influenced in ways of which we are not yet fully cognizant. What we shall find, if my confidence proves justifled, is that our most important acquisition has been, not skill, but insight, insight into processes which have become more penetrable to observation because of the scale and the speed with which perforce they have been developed, Insights such as these doubtless can be commumicated, but means for transmitting them without distortion may be long in devising."-D. $F$. Cavers. 
tion in terms of "the law" came into being very naturally, and in its day was sound. While case-instruction was still giving off its by-product values automatically, the natural focus of an instructor's attention was the organization of "the law" for teaching and for learning. "The law" was also at that time in desperate need of such organization in simpler, clearer terms. But in due course, and without anybody noticing in particular how it has happened, "the law" has simply become a presupposed subject-matter, almost the whole presupposed subject-matter, of our conscious teaching. Save for odds and ends all else has come to be left to the by-products of case-instruction. So strongly marked is this point of view that discussion of curricular revision still moves almost exclusively in terms of adding or rearranging substantive content: we may throw Mortgages and Suretyship and maybe something else together into Security, or throw Agency, Partnership and Corporations into Business Organization, or add Labor Law, or substitute Municipal Corporations for Damages, or go into Public Law by adding a course in Administrative Law or in Governmental Regulation of Business. Whether to do such things is what we discuss, when we are discussing the curriculum. True, this may be accompanied by efforts at more effective organization for teaching by "functional" groupings of material, bank collections, let us say, being taken out of Trusts and added as a part of "Banking" to Negotiable Instruments. Yet two facts continue to dominate: the first, that choices are made in terms primarily of bodies of law which compete with one another largely in terms of their supposed importance as bodies of law to be learned while a student is in school; the second, that the competition is getting constantly more intense, with more bodies of law competing, and with each one growing steadily in regard to how many topics "it" includes and how fully the branching of each topic demands to be developed. The resulting bulk of information to be absorbed combines with the drop-off of effectiveness in "indirect" teaching of "legal method" to force fresh attention to other things than substantive law alone.

What your Committee are forced to challenge, therefore, is any assumption that the subject-matter of a law curriculum can be soundly determined in terms of the importance of learning the law of one or another "field" by case-instruction. What we suggest in substitution is a choosing among the various bodies of law which now are or which later may be conveniently organized for class-study (each of them "substantively" quite important enough) in terms less of relative importance of their particular subject-matter as such than of their convenient utilization to restore the lost values of apprenticeship training or of other 
training in legal skills which are plainly needed by every law-graduateskills, so far as may be, of reasonably general application.

We suggest that there has naturally but unfortunately slid into the curricular picture a somewhat curious error in orientation. What we are training students for is not knowledge of the law, but practice of the law. Practice is an activity, a skilled activity, an activity to be carried on according to craft-traditions and craft-standards of ideals and skills, an activity which involves expert knowledge and use of the law and also other lines of expertness, but which involves all of these not in the abstract, but in concrete work over the concrete problems of a client-be the client an individual, a corporation or the government. Now it is very queer that a training for such skilled professional action should insist on centering its conscious thought primarily on the acquisition of a single one of the many tools for such action: to wit, on knowledge of the law. And it is even queerer that the centering of a training for a life-work should be upon what experience shows to be the least permanent of all the tools of practice. Positive law is in flux. It has rarely been in flux more speedy or far-reaching. Some of its deeper principles, we may be sure, are not in flux; but the art of applying deeper principles to concrete, complex and novel situations is a skill, a skill which is testing the powers of our best lawyers and officers of the law. Knowledge of the positive law thus obsolesces, even when it sticks in the student's head; but most of the skills of the lawyer's craft obsolesce slowly, if at all; they are amazingly adaptable to wholly new situations. ${ }^{9}$ Shrewdly the classic case-instructors saw skills to be the heart of caseinstruction. Skills, plus the deeper principles, and skill and practice in application of the deeper principles.

It is of course true that a working knowledge of our basic positive law is an essential part of any lawyer's equipment. We go further: it is a fact difficult to blink that our graduates need much more of such knowledge than they are now getting in school. It is also true that added case-courses in new subject-matter in a longer curriculum can give them more-a little more. But it is true no less that case-instruction is a singularly slow and wasteful method of imparting information about rules of law to any student who has once mastered the proper "byproducts" of case instruction. And it is unfortunately true today that no set of courses given in case-style or in any similar style can alone and without supplement give a student in three years or in five the informa-

9. We are not concerned with what psychologists have written on "transfer" of training. Horse-sense observation shows that the skills we are talking of serve a lawyer throughout his work. 
tion about the state of the law which he really needs. How much he can get by other means, and get fast, we observe when any of our students settles down to prepare for a good bar examination on material which he has not had time to "take in course".

It thus seems that sound curricular construction, after a first "training" year centered on seeing to it that the older "by-product" values of case-instruction really get across throughout the class, calls for initial recognition that the needed information about the state of the laze cannot be given in course. Such recognition has two necessary consequences.

The first is that much information about the state of the law which is desirable or even needed will frankly have to be left out of central curricular thinking. It can be left to elective courses each of which by the very fact of becoming elective is conceded to be dispensable to any particular student. Or it can be cut out wholly, and left to individual bar examination review. Or it can be organized for study with the help of syllabus and selected readings, with or without brief lecture treatment (e.g., (a) introduction to the problems, (b) detailed treatment of one or more segments, to avoid any feeling of competence based on mere surfaceacquaintance, (c) summing up in wider perspective), and with or without consultation hours for students' questions arising from their reading.

The best treatment is probably a combination of the first and the third, drifting as facilities may permit into the third alone. For it must be recognized that, as yet, reading material well adapted without the aid of a case-course to inform the student about the state of the law is rather scant and scattered. As yet, it is particularly difficult to find such material gathered into those larger blocs whose intelligent integration is one main need. It is also difficult to find such material in treatment at once brief enough to be compassable and yet incisive enough to cut below the surface. Clark on Code Pleading suggests the type of book needed for the purpose, or Vold on Sales. Such a more intricate and masterly study as Prosser on Torts is yet built primarily either to supplement a case-course or for use in the practice, rather than as a general preparation for approaching the practice. It may be further noted that any book built to provide students with needed legal information without the aid of class discussion will fail of its full possibility unless it deliberately takes as one focus the "danger spots" presented by the field to the practicing lawyer, marking for the student a survey-map not of the law alone but also of where to look for trouble and of where, when he meets it, he will meet the need to inform himself promptly and with a depth which little school instruction can offer.

What is clear is that until a sufficient supply becomes available of good books of a novel type, the problem of providing the law student with 
the information which he needs in the time at our disposal cannot be soundly solved, whether in standard course or not. We now use stop-gaps which only partly stop the gaps. We must continue so. But it pays to recognize that situation. The piling up of more standard case-courses does not cure it; that only expends further curricular time for an inadequate return in information.

The second consequence of recognizing that it is simply impossible to provide every student by way of case-class with adequate information on the state of the law is to force selection of some other criterion than "importance of subject-matter" as the basis for determining the standard offerings. ${ }^{10}$ In considering a substitute criterion one recurs to the basic fact that what we are training for is not mere knowledge of the law, it is the practice of law. One recurs to the fact that apprenticeship demonstrates many skills of the legal crafts to be teachable. One recurs to the sound prevailing belief that the heart of good case-instruction lies in the communication of a whole series of skills. One looks for lines of craftman's skill which are, first, identifiable, communicable; second, within the knowledge and teaching power of law professors in general; third, capable of instruction in classes run with case-books or supplemented casebooks; fourth, capable of such instruction without material disruption of the current law curricula.

We suggest here certain lines of such skill, each of general applicability. Each is capable in conjunction with existing materials and minor supplement of becoming the focus of two, three or four units of effective instruction which will carry down throughout a class. Introduction of all the lines in the upper two years would disturb the structure of existing curricula almost not at all. Introduction of any one or more holds promise of toning up students' interest in gratifying fashion, once that first fourweek period is over during which an upper-year student balks for a while at having to learn anything new at all about how to learn or how to work. After two years, even this balking fades: it becomes a new tradition that all the learning about how to learn is not limited to a first semester and the law review.

\section{A. Statutory Construction}

The first and most obvious of these skills is statutory construction. It definitely does not develop adequately as a simple by-product of our

10. By "standard" we mean here de facto compulsory in substance: whether because officially required, or because there is no other offering open, or because student opinion makes an offering substantially inescapable, or because the choice runs between two or more offerings all of which are built to purvey the same values (e.g., Sales, Negotiable Instruments and Bankruptcy, if each should be taught as centrally a training in statutory.construction). 
current case-instruction, and few courses in Legislation give it full or systematic attention. It plainly calls also for teaching against a thoroughly understood single body of material, not against a spasmodic series of different problems; for only when the different types of construction are used upon the same type of material does their essentially alternative character become fully clear. The N. I. L. is at present as good a body of material as exists for this purpose. ${ }^{11}$ It contains, for instance, excellent sections, some of them with accidentally prophetic language cleanly "covering" wholly unforeseen problems and yielding fine results on purely verbal construction; it contains also awkward sections which give no such results; it involves gaps in some spots, while other spots are covered exhaustively; it has sometimes untoward language in regard to problems not considered in the drafting, language which one has to construe to avoid, or to strain into the best sense it will bear; it has a caselaw background and an accumulated case-law of often conflicting interpretation; it is in the main amazingly systematic, presenting magnificently the problems of interlocking sections, and those of consistent (but also in spots of inconsistent) terminology; it presents the problems raised by successive adoptions and constructions and by differential clarificatory or corrective amendments; it interlocks with other statutes saved or repealed or modified by implication; it is up for revision, which gives meaning to suggestions for betterment. About the only line of construction it fails to offer is construction by way of the legislative record and the preamble, with their conflicting doctrines; and even those are present in part. In addition, Steffen's case-book offers three hundred or so pages of pre-N.I.L. cases presenting problems for construction with much of the needed background of practice and policy made available, while the student is left largely on his own to develop an answer out of the statute by his own study, without a court presented as tracing the road before him to be merely "followed". And it is to be remembered that if the student, accustomed to "following" opinion-discussion, is to be awakened to fresh and intensive reading of statutory language on his own, he must

11. "Although I concede that the N.I.L. could be exploited much more fully than it has been as a medium for instruction in statutory construction, I think there are several reasons why reliance on it for this purpose should not be recommended. Here are a few: (1) Attention to the product, with its bread-and-butter flavor, is very likely to distract the student's attention from the by-product. (2) Not only is the statute unlike most contemporary legislation in style and content, but I doubt that any statute which to so large degrce is declaratory of common law can be a representative source for the study of current problems of statutory construction. (3) The capacity of the law schools to convert the new into the familiar should be noted in this connection; nothing would be more congenial to those who dislike the disruption of existing curricular structures than the thought that their obligation to be 'progressive' could be discharged, pro tanto, by good old Bills and Notes."-D. F. Cavers. 
be faced head-on with a problem, its background, and the statutory text, with the work of solution up to him, with no lulling authoritative interpretation to merely "follow" in comfort.

At this point it is worth while to recall that case-instruction has two wholly distinct aspects and lines of value. The one has to do with the study of concrete problems, concretely presented for work, for discussion, for development of their wider implications, for testing out on them of theories or of other generalizations. The other aspect, which in Torts or Contracts happens to coincide with the first, is the development of the law of the field and of case-law techniques for handling authorities, out of study and discussion of judicial opinions. The office of this second, pure judicial opinion, aspect of case-instruction is exhausted when the whole of the class have had the relevant techniques ingrained into them. The office of the first aspect, that of working by way of concrete situations and problems, is never exhausted. But neither is there any end to the variations which are possible upon the first aspect, or to the fruitfulness of well-chosen variations. Nor is there any necessity for building up all generalizations out of thê concrete instance. Generalizations can just as well be provided in advance and either tested upon or used upon concrete problems. Indeed, with due deference to a tradition (or myth) to the contrary, the opinion may be hazarded that after the first month or so the teaching of a man like Ames in a course like Trusts came very close to being an exercise in application of a few known and clear principles to a variety of situations presented by the case-book.

Thus, today, in the study of statutory construction it is possible and useful to put into the students' hands in advance a statement of the standard rules and canons, with their direct internecine conflicts. As: (a) The preamble is no part of the statute and is to be disregarded; $\left(a^{\prime}\right)$ The preamble shows the purpose of the statute and all the language must be read in the light of its purpose. There is no gain in learning rules like these by wastefully ploughing through a case or more per rule. What is needed is to know that they are all present, all correct, all on tap, and then to set to work on a whole series of concrete controversies under a concrete statute and to practice construction and articulate defense of the construction achieved. There is gain in both interest and sharpness of discussion from having some students construe for the plaintiff, some for the defendant.

A course in statutory construction in the second year not only capitalizes but reinforces the first year work on the dogmatics of pure caselaw. Whatever material be used, it will turn out a class probably somewhat less well heeled on the relevant positive law than if the course had 
been taught in standard case-fashion. In substitution there is some reasonable acquaintance with the selected field of law, enough acquaintance to make reading in that field workable and easy. More important, there is in addition a command of a set of techniques which every lawyer needs at all times and which half or more of our students now graduate without commanding. But the full built-up knowledge of the instructor in the field concerned is capitalized, for it is judgment based on such knowledge which guides choice among the competing technical possibilities of construction. And there is also capitalized a competence in the skill of statutory construction which every such instructor now has, but which he rarely fully exploits in class: a skill which for instruction purposes remains today a half-used asset.

\section{B. Appellate Advocacy}

The second skill to which we advert is that of appellate advocacy. As curricula are now organized this would in most schools have to come at the cost of some other course. It is not readily teachable in conjunction with the teaching of an extended body of subject-matter. Cases for real briefing should be rested on a real record, the relevant law should be soundly explored, the statement and treatment of the facts takes time and takes repeated redoing: one cannot therefore hope for a respectable job, squndly redone after critique, on more than three cases or so in the course of one semester.

There should be no doubt that advocacy is an art capable of communication; both the Greeks and the Scholastics in their day demonstrated that it is. Nor should there be doubt that the particular phase of advocacy found in our own apellate brief (with or without the addition of oral argument) is a distinctive art which does not depend upon peculiar expertness in any given legal subject-matter; else there would be no such thing as general appellate practice. Neither should it be difficult to bring together for general use an adequate body of formulated basic principles and usable lines of advice in argument. Walters' book on Brief-Writing is excellent, as is Davis' speech on the oral argument on appeal; Carnahan developed useful work along this line at Kentucky; the Yale moot court system has long operated under skilled and articulate faculty instruction in argument; Llewellyn and Wechsler have given the matter attention at Columbia; there must be many others who have worked at it and whose experience and conclusions could be assembled. Indeed any teacher of law, by the very nature of his training, is competent to take over critique and guidance of brief-making, if only enough of the horse-sense "principles" are put down on paper to guide 
a student's groping and give him pegs on which to hang his experience. ${ }^{12}$ The major difficulty lies in developing techniques for instruction of a class of any size without a crippling expenditure of faculty man-power. It may be suggested that the necessary copies of a single record can be procured at reasonable expense by making arrangements with regard to cases about to be appealed, the outlay being limited to the cost of extra copies which can be made on the original run; that the class can be divided into teams of plaintiff's and defendant's counsel; that the preliminary research work is capable of subdivision and pooling; that critique in class on the arrangement and phrasing of points can be handled in regard to a series of student drafts without too much time expenditure; and that detailed critique of a single brief on each side (not only on first draft but on redraft as well) can be handled to the definite advantage not only of the writing team and their assigned adversaries, but of any other teams who have worked up the same case. The other teams tend indeed to produce a sharpened critique and discussion from "the floor". There is also open under such circumstances a comparison with the actual briefs that proceed to get filed in court and, if desired, discussion with the counsel concerned.

One thing we beg leave to emphasize: in all work which calls for writing by students, the lesson of apprenticeship training is that it is the redoing after critique which is the crux of the learning. It is not enough to know or to see; the student must stay with his doing until the job is good. And any conception that interest will lag is overcautious error. On the side of pure interest, the sense of accomplishment which comes when "she starts to really roll" is enough to stir almost any student. The first redoing is resisted, but the experience of one real redoing kills the resistance for the future.

Redoing, moreover, carries a vital collateral advantage. A good writing job in law calls for so much time in general preparation on the

12. Even the simpler and more obvious "principles" prove to need teaching and practice. Thus, that an argument is addressed not to its author, but to a specific tribunal and must for effectiveness move in terms of what will appeal to and persuade that tribunal. Or: the principle of "limited span of attention" of any tribunal, with corollaries: the value of simplicity of thread; the value of points which cumulate instead of scattering; the extra-interest which the statement of facts arouses, and the importance of making that statement frame the issue favorably, and of an arrangement of facts which drives forward. Or again: the value to a legal thesis of a phrasing in language both simple and familiar; or the power, in an answering argument, of a positive thesis which neither accepts the ground chosen by the other party nor loses momentum by a succession of denials or explanations. While most beginners sin against such principles, it is amazing how soon they learn to move with relative effectiveness; it is no less amazing to see involuted sentences shift into an ordered series of simply stated ideas and to watch the punchword moving into punch-position. 
facts, the law, the soaking in background, that even a willing student finds the time-burden oppressive unless one holds down the number of jobs to be done. Redoing - and at need a second redoing from ground up-is a means of intensified training which capitalizes a single initial preparation. Reexamination of authorities, if needed, or supplementary research, imposes for example nothing like the load of working up a whole new case. And we must not forget that "experimental" courses looking toward practical skills have with saddening frequency "broken down" under the time-burdens which the instructors have imposed. What we are suggesting is that the more sustained milking of a single problem, capitalizing at once the lessons from apprenticeship pedagogy (redoing after critique and for new critique) and from case-instruction (the value to a larger group, properly prepared on the material, of intensive discussion with some one or few) can bring this matter of time within manageable compass. Indeed, if we may jump ahead into the material immediately following, it is frequently practicable to build a counselling problem and work it out on the same material which is planned thereafter to set a problem for briefing.

\section{Simple Drafting and Counselling}

The third line of technique suggested is simple drafting and connselling, coupled with critique of forms. There is no reason why this cannot be substituted on the pleading side for some of the current casework in the first year Procedure course, or why the drawing of papers cannot be added to the second year course in Procedure. There is no reason why, as a set of exercises in drafting instructions for the jury, such work cannot be incorporated into Torts. But over and above the simple exercises which can thus give life to first-year case-courses and make individual words and phrases take on individual meaning, there is need for sustained practice in elementary drafting, coupled with critique of available forms (which last is a most effective introduction to the problems of phrasing) and coupled with simple problems of counselling. Again much of the critique can be done for the whole class at once, on one or more of the drafts; again the pooling of work by teams is practicable. As a separate course (say, as at Yale, in Office Practice, or as at Columbia, in Legal Problems, with participation of the lawyer who furnishes the problem) this again costs curricular time, but again, not too much of it. The same is true if the work be concentrated within a single situation-area (e.g., banking, regardless of the "fields of law" concerned) or within a single one of the broader fields of law (estates, security). For it is not positive knowledge, but method, which is the 
heart of the job. What is important is that along with the intensive training in reading, writing (and of course above all in rewriting after critique) there shall go an adequately thorough preliminary canvass of the relevant law and a body of "principles" of counselling which reach for general applicability. Even the thorough preparatory canvass of the relevant law is important first of all as a "principle" of counselling. It is important only second to provide a foundation for the job in hand, and in that aspect a student learns the vital distinction between the thorough job which consumes a thorough job's time and the job which requires action by noon tomorrow, where he comes to see the value of accumulated knowledge on tap, the value and technique of "rapid" library work, the problem of responsibility for knowing where his knowledge is not enough, the uses, dangers and peculiar art of such consultation guarded against loss of client. In either aspect, "rapid" or thorough, the canvass of the law makes vivid to a student how different is vague general knowledge of the law from accurate specific knowledge oriented to the particular problem. But it is relatively immaterial what field of law, what specific knowledge, may be concerned, if only enough background of practice, need, nature of the client and the like be provided to sharpen the problems of counselling as such, and as a concrete, living job.

At first blush, the development of communicable "principles" of counselling appears materially more difficult than does the equivalent task in advocacy. For one thing, it is our ingrained habit to think of counselling as completely dependent on expertness in a particular field of law. A Property man distrusts his own competence to counsel in a commercial case, and vice versa. This in itself is easy to deal with: a teacher can always procure any needed special competence by invitation, whether from a colleague or from an outside lawyer. One can, moreover, build a counselling course on and out of his own experience. The much greater difficulty lies in the fact that we have come to see our own counselling devices and skills much more in terms of the particular field of law or practice than in terms of their general implications for counselling at large, and that is in material part a false seeing. For so much is clear: a skilful counsellor can make good headway in a novel field, and fields are opening everywhere today in which no man has had experience because those fields are new ; moreover, in any but highly specialized practice our graduates must learn to make their way in fields which may be old to many, but which will be new to them. It is the art and skills of doing that which pose the central problem; particular wisdoms in particular areas must be treated as "case-material" from which general implications are to be developed. Thus for instance such bank- 
ing adages as "Get the waiver of protest on the face of the note" or "Have the partners individually indorse the partnership note" or "One solid guarantor means quicker collection than six" have reason under them; the two first have reasons in legal technicality, the third has reason in practical experience with men who stall by being "willing to do their share" as soon as the weakest or most unwilling "co" has been gotten to pay up. But the wider meanings of the first two adages go to such things as the general problem of maximizing security on the one hand and of decreasing sales resistance by the discovery of simple, inconspicuous devices, raising the companion question of when an elaborate machinery is both necessary and practicable; while the last poses rather neatly the ancient difference between "legal" security (however elaborate and "tight" the guaranty form) and practical security, and hooks into the theory of advocacy by showing the advantages of concentrated pressure as against pressure diffused. Our suggestion is that some such general "principle" or wisdom or "philosophy" of counselling is implicit in each of our more concrete wisdoms, and is merely waiting for development. Such development is the teachers' province in which he can add to what any but the most articulate of skilled practitioners has to offer.

Indeed much has already been made articulate and gathered for suggestion to any instructor who wants it. The lectures once given at Cornell on the drafting of instruments are for example full of meat; the work done at N. Y. U. by Tompkins must have left behind communicable results; the New York Practicing Law Institute has valuable annotated forms in current use. In a word, again, scattered through the country, there are waiting to be brought together shrewd observations which both enliven a class and give good guidance for work, and which raise hard practical problems for discussion: When, for instance, is the solid counsel the right counsel that a simple letter in business language is worth three formal documents? When, on the other hand, is a formal document all but necessary ?13 $^{13}$

It will be noted that the three foregoing suggestions center on what can be lightly scorned as mere exercises in reading and writing. Your Committee do not feel any such scorn to be justified. Again the bluebooks do not show too many of our students to be so effectively literate that

13. Consider the problem of the client who does not see that any simple document is worth paying for and the technique of both educating him and winning his allegiance by first going over with him the legal difficulties to be faced and met without stirring up the other party's fears. Contrast the situation where formal expression, if intelligible, and full expression, are exactly what is needed to impress the other party, or to hold him in line without need for litigation. 
reading and writing, the heart of a lawyer's work, will prove wasteful study. ${ }^{14}$ Questions on the very examination are again and again misread. Answers are too rarely organized with plan or phrased with prècision. Moreover, legal literacy is a separate branch. He who can think law with cogency can yet be woefully weak in stating facts with interest, with drive, with the subtle flavor of the inescapably just cause. Excellent logic can fail of all persuasiveness in presentation. Few indeed are the students who, given a good counselling idea, can clothe it in language at once accurate, brief and moderately acceptable to the other party, persuasive of its fairness to a judge. If they were no more than exercises in reading and writing, then, these suggested courses would still be as justified in their claim on curricular time as are the exercises in sermon-making among the divinity students or those sometimes superb courses in making engineering reports which yield a clarity, order and conciseness of expression most lawyers can envy.

But packed into each of the courses suggested ${ }^{15}$ are two other things. One is an opening up of the meaning, of the living use and handling of legal material, an opening up of the actual working integration of "law", fact-background, and craft-skill. This excites. It excites a student caught in the doldrums of the upper semesters. It carries over in material part into the case work in other courses, making those courses pose new questions that it is good to have posed. The other thing is a revivifying of the word on the page. Once you have learned by sustained statutory construction "to read a sentence like a lawyer" and have carried the learning over also into instruments and practiced the art there, too, the dull or sloppy eye now common to the fourth or fifth semester student is gone forever. That gain, carried throughout the upper-class student body, would alone justify a full semester's expenditure of teaching time. Again the pack-pace lifts, in all the other work of the standard courses.

Brief-writing gives different collateral results. After a sound training in argument, every judicial opinion opens from a new dimension: as an example, good or poor, of presentation and persuasion. That is of some help to other classes. But what helps more is the student's gain in facility of organizing his own thought.

14. If reading and writing are not effectively available in our students as we get them, we still cannot shift to prep school or college the responsibility for graduating them from law school without solid skill in each. And my own experience is clear that both reading and writing can he hugely and with comparable teaching energy toned-up or even taught, along the lines suggested.-K. N. L.

15. The suggestions contain no effort at completeness. We have not for instance touched on the problems surrounding trial, as handled for example by Cherrey at Minnesota. 


\section{The Problem of "Public" Law. 16}

The foregoing deals primarily with need and methods of recapturing the basic values of "classic" American case-instruction, and of developing other closely similar and no less basic values with which "classic" case-instruction dealt only in passing. But it has long been clear that the whole set of assumptions on which the classic training rested were insufficierit to full and rounded training for a lawyer's work. It was the very narrowness and tightness of those assumptions-fixed, definite "law"; fixed, definite, sharply phrased, unchanging principle; fixed, definite, single method for finding the predetermined single correct answer; policy as either already fully incorporated into legal principle or else irrelevant to legal thinking-it was this very narrowness and tightness which made case-instruction so hugely and automatically powerful in its inculcation of the techniques of case-law "legal method", "legal thinking". The classic areas of subject-matter were those of "private" law and of case-law : all relatively fixed and slow moving, relatively simple in subject-matter and background, relatively established in their basic policies, relatively confined to judicial action on both the regulative and the enforcement sides. Disturbances of the pattern of work and thought came in as soon as any one of these attributes was lacking. Any new premise was very troubling (liability without fault; promissory estoppel). Any new and complex background was no less so (the professional surety; the corporate mortgage securing a bond-issue; today the making, renegotiation and termination of war production contracts). Wide-scale statutory modification was uncomfortable, even when the statutes ran more or less in families and were of moderate age (statutory criminal law, the recording acts, uniform commercial acts, and

16. We do not suggest that there can be any law which is not in material part "public." But for purposes of curriculum there is a fairly sharp cleavage between material in regard to which conscious quest for sound policy dominates the picture and material in regard to which the main lines of policy are relatively settled. Today this latter situation is still found in sufficient degree in the older standard "private" law fields to make them worth contrasting with the relatively open-policy fields which include most material currently thought of as "public." The pedagogieal problem, whatever terms of description be used, is one of finding law settled enough and policy problems simple enough so that the student's earlier training can be concentrated on the utterly basic phases of accurate legal technique. In this aspect workmen's compensation and the statutory variations in the law of homicide offer advantages similar to those of large portions of Contracts, while such aspects of the latter field as deal with lop-sided forms or the making, renegotiation and termination of war-production contracts acquire dominantly "public" flavor. The presence of a specialized administrative agency may bring in crucial problems of administrative regulation and enforcement and of controlling both, as with the N.L.R.B. or the Treasury's handling of foreign funds or the mixed-agency handling of passports, immigration and deportation, or may offer relatively little in the way of special problems, as where policies are settled and administration noncontroversial. 
devastatingly the wide-scale statutes of the present century). Constitutional law, for instance, though it was as fundamental then as now, and though by the '90's it was becoming a major tool of private practice, was yet a late-comer to the standard curriculum, and had to fight its way in: "This is not law at all, but politics." Yet over the years "Bailments and Carriers" became "Public Utilities", "Restraint of Trade" appeared, and Labor Law, and Administrative Law, and Legislation; even the older "private" courses insisted on opening questions not only new, but different in quality in that they forced the quest for sound policy into conscious attention, and this even in the field of purely judicial action. Taxation has meanwhile grown into a factor so conditioning the whole law of business and of property that its aspect of regulation (intentional or unintentional) looms as large as its aspect of revenue-production or its pure technique. We have been presented, in the States as in the Federal System, with the problems of the specialized administrative agency as a new center not only of the thinking of the lawyer as a skilled citizen, but of his very activities as a lawyer. Even such once moderately simple pictures as the mortgage on a house and lot or on a farm are almost remade by the introduction of a series of governmental financing agencies; the bank collection picture, with deposit insurance added, and with Federal Reserve deposits as a dominant medium of ultimate "remittance", hardly resembles that envisaged by the classic rules and cases. Plainly, however superb the classic methods and material to accomplish things which still need accomplishing, they are no longer sufficient to a rounded training for the practice. Plainly, also, as one rethinks the matter, the new needs run not only to additional material, whether bodies of law or a wider range of relevant fact, but also to new points of view and to additional types of craftsman's technique. Curricular movement attests this on all hands. New material: labor relations, governmental control of business. New range of fact: the background of the modern constitutional case or of securities regulation or of workmen's compensation or of any "open" policy question any one of us undertakes to explore. New points of view : $77-\mathrm{b}$, collective bargaining, "the public point of view" in general. New techniques: legislative drafting, administrative procedure, our steady but still uncoordinated efforts to develop not merely a quest for policy but an intelligent and communicable line of techniques for going at the job of making a sound policy judgment (large or little) and then for criticizing or building a measure in terms of a given policy.

Three decades of unrest and step-by-step modification attest our recognition that the classic methods and material have proved not to 
be enough. The same three decades of hanging on to the classic methods and material attest our belief that both of these continue to have body and persisting value. But the new demands grow daily more insistent, and they daily show their warrant for insistence.

The immediate consequences for the curriculum are two. The first is time-pressure, and in three distinct aspects: (a) The old and standard courses require gain in bulk to remain intelligible in their application to modern life; they open new sub-heads, they cut across into "other fields", their rules subdivide and ramify explicitly (professional surety versus friend-surety) or implicitly (sale of goods in current commerce versus "sale" in payment of an old debt) or both (family corporation versus corporation built on general financing). (b) The old courses call not only for developing "the law", which takes time enough, but also for a critique of the law in terms of policy, and call for sufficient digging into fact background to make the critique have meaning. There is no other way to prepare the student for current flux or for impending changes. (c) The directly "public" material presses for direct treatment, and its bulk swells daily. That growth is not only in terms of what is there, but in terms of its relative importance both to understanding our legal system in any part and to coping with the practical problems of the lawyer's daily services.

The second consequence of the relentless incursion of the "public" phases of law is in some ways even more troubling. Judgments of faculties will differ in the future as in the past on how much and which part of this "directly public" material simply requires to be assigned a course; but judgments cannot differ that enough of it requires curricular allotment to squeeze heavily upon our more traditional offerings. It is that we are being forced, willy-nilly, toward providing for ourselves and our students a thing uncongenial to our minds and for which our traditions provide little satisfactory foundation: that is, a whole-view of our law and of its place and function in our society. This is uncomfortable for a number of reasons. One is that we have grown used to and contented with expertness in what are amazingly narrow fields. Where a European is a specialist in Civil Law (say, in our terms, Property in all aspects, equitable or legal, Contracts, Torts, Agency, Estates, Family, Statutory Construction and General Theory of Law) or in Commercial Law at large (say, Business Organization, Commercial Paper, Bankruptcy, Admiralty, Marine Transportation, Insurance, Marine and other, Commercial Sales, Regulation of Accounts and Business, Theory of Business Customs, Comparative Law of all of these and their relation to Civil Law proper) we become specialists in a few smallish "fields"; or, in 
the less traditional "public" area, we grope to become specialists in the world at large. In the first case we lack the necessary information, in the second the necessary precision, for a sound whole-view; nor does our literature offer too much to help us. Another reason for the discomfort is our habit of case-wise thinking and of ad hoc reasoning, our distrust of systematic generalization on the grand scale, our case-lawyer's insistence on bringing any abstract statement of goal down into the field of means and measures before we feel that we gain any lawyer's grasp of its meaning. A third reason is that no view of the whole can be achieved which does not run in terms of a political philosophy; so that the very quest for such a view opens up in unpleasant sharpness those conflicts in political point of view within any faculty, and as between faculties, which a common interest on the level of "legal" craftsmanship has long made it relatively easy to keep within workable bounds.

Yet the need for moving toward a whole view is becoming unmistakable and the responses to that need are evident on all hands: The little battles over the proper lines of organization of a course-book and over what type of material is proper or wise for inclusion in one, those were a beginning. The introduction of "policy" discussion into the class-room has been thrusting most of us toward a realization that underneath policy judgments on little questions lie deeper policy judgments on large ones, which also call for being made explicit and for testing. The battles over administrative procedure show as clearly that our received judicial procedure is not adequate to all our procedural needs, as they do that . some of the principles embodied in our received judicial procedure are indispensable to any procedure under our ideals of government. But those same battles show also that we have not yet found out either exactly what our ideals of government are or exactly how best to implement them. It is no accident that Jurisprudence has recently become for law professors and for curricula a burning issue whereas three decades back it was viewed as musty siliiness. It is no accident that jurisprudertial controversy has tied into the fundamental questions that surround the administrative agencies, the Supreme Court, the war. It is no accident that the much discussed fourth year of law study centers on broader vision, wider outlook, enriched background. It is no accident that the last decades have seen the bar for which we train worried and at times verging on despair over their place and function in the community, even over their livelihood. It is no accident that pressure-groups loom large and that law as such no longer has the majesty of old. All these things, little and large, speak to a situation in which the received traditions of law, of legal thinking, of legal practice-and of training for all of 
them-are facing new problems which old methods are not in themselves enough to solve.

Such a situation is always marked by attack on the old methods and ideologies as if they had become hopelessly inadequate, utterly useless. It is always marked also by defense of them as if they were impeccable and completely sufficient. Always the attacks are scattered, and come from several uncoordinated directions at onee; each substitute first proposed, however sound in perception of some real and needed value, is but half worked-out, is partial, is vulnerable. Always the defense is over-general and includes blindish or inert protection of many things that badly need readjustment, and yet rests on a sound feeling that the old includes things that it simply will not do to lose. At this period when we face drastic need for reorganizing our teaching methods in order to save time for our returning servicemen, the need also so to sharpen methods as to get results across to men who have lost the trick and habit of book study, who have been conditioned to action and to thought in terms of action-at this period it is our singular good fortune that the exaggerations of our controversies have already had their due decades to be weeded of the grosser errors on both sides and to open a road into the areas of soundness on which most of us ean agree.

\section{8. "Skills" as an Approach to "Public Law".}

Indeed the traditions of American legal work and teaching in the last three generations strongly suggest a solid avenue which leadș through the "public law" problem. The basic values of case-instruction offer the first suggestion. Those values lie in effective class-room training in some one or more of the fundamental skills of the lawyer's craft. To secure such training we have regularly and willingly sacrificed class-coverage of body after body of substantive law which it is unquestionably desirable for every student to be exposed to. A glance at the digest reminds us of topic piled on topic, all of general value, which we have never thought of including in a curriculum. A glance at the law school catalogs shows lists of topics "offered" but many of which the limited student time requires any student to leave "untaken". Consider as quick illustrations the modern importance of municipal corporations, school laws, public contracts, J. P. or municipal court or federal practice, agricultural finance, marketing organization, zoning and building regulation viewed in terms not of constitutional validity but of content and effect. Our universal practice has been to select what as against the mass remains a relatively small number of substantive fields for class treatment, and to rest content therewith. "Method" and "basic 
theory" have been the fundamental product. There has of course been effort, rather successful, to choose fields of substance which are "basic", or at least among the basic.

Your Committee suggest that a similar approach is both called for and workable, to meet at once the "public law" needs and the pressure of time. There are lines of skill which are of reasonably general application and which can and should serve as the indispensable features of training in "public" law, as case-law "method" must in sound case-instruction. Constitutional Law has already established itself as one basic body of substance-and with one interesting and highly useful by-product: the focussing of students' attention, for once, not on "the courts" but on one particular court manned by particular judges. It would be unfortunate if the peculiar value thus gained for instruction (and no teacher who handles both Constitutional Law and a general case-course can miss the extra vitality that flows from this added concreteness) - it would be unfortunate if this peculiar value should be overlooked in the other public law work. The problems of administrative procedure focus for instance around two strikingly diverse types of administrative agency: the established agency, where the dangers are woodenness, routine, slackness, established lines of influence and the like: policies which are too reckonable; on the other hand, the new agency, where the dangers are over-zeal, arbitrariness, ignorance, inexperience: unestablished, unreckonable ways and policies. The problems, the lines of sound administration within and of sound control from without, are better developed out of concentrated concrete material from one or a few agencies of each type than they can be out of scattered material that bounces from one to another of many agencies. If there is any lesson for "public law" work from our older case-instruction it is the need of full understanding of background before the concrete material can yield its full value for generalization; if there is any lesson from the first great public law course, Constitutional Law, it is that major concentration on a particular concrete going organization adds a whole new dimension to study for the law.

"Administrative procedure", on the other hand, is a topic rather than a line of craft-skill. We suggest that within that topic four quite distinct lines of craft-skill can be discerned: (1) dealing with an agency in the pre-"litigation" phase; (2) handling a matter before or against an agency in the "litigation" phase; (3) administering, within the agency; (4) administering as against those with whom the agency must deal or struggle. Each of these has aspects wholly individual to a particular agency; cach has, no less, aspects of general applicability which can be 
learned from either the performance, from the misperformance, or from both, of a particular agency. A focussing of class-study on these craftskills not only builds naturally out of our experience in case-instruction; it also provides a useful machinery for reducing to manageable proportions the intra-faculty conflicts of political philosophy which any treatment of "public law" threatens to engender if the treatment focusses too exclusively upon merely the substantive law-or upon administrative procedure-dealt with in the light of policy. For the nature of a lawyer, even when dealing with hypothetical material, is to be moyed to understanding of and some sympathy with the problems of his client. If, then, the approaches and skills sought to be developed in class are skills on each side, some roundedness of approach is well-nigh inevitable. Indeed, in the case of an agency like the N. L. R. B. they are skills clustering around at least three sides: a management's representation, a union's representation, the agency's representation.

Though different in objective and often in policy, the diverse lines of craft-skill just suggested yet have a common basis. These administrative agencies which are to remain with us, whether any one of us regards any one or more of them with enthusiasm or with disgust, have been with us long enough for one basic principle for dealing with them to have emerged' and to have already become the foundation of reputationproducing law practice. That first principle is that to get from an agency or to get by an agency what your client needs (unless the agent or agency is plain corrupt) you begin best by acquiring a thorough understanding of the way the agency operates and of the premises on which it proceeds about its work. That, and nothing less than that, sets the stage for sound negotiation, sound persuasion, or sound battle. But the same is true if one's interest be in furthering or improving the operation of the agency. Dealing with an agency, handling a matter before or against the agency, administering the agency within or without, rest thus all three on the same common foundation of understanding the situation which called the agency into being, its underlying structure of law and organization, its premises, policies and methods of operation and the problems opened thereby. Not only can these lines of skill thus be studied, in part, together, but more specialized attention to any of them enriches the study of each of the others. And they are capable of study both in specialization and simultaneously. For our old case-tradition, with a plaintiff opposed to a defendant, offers a two-way attack into the handling of any specific problem: from the side of the regulator and from the side of the regulatee; and there is no reason why class discussion cannot be developed along two such lines at once, particular students 
(according to desire or by assignment) specializing either in one phase or in the two in alternation.

\section{9. "Widened Perspective".}

All that has been said leads up to the question of the "outlook", "perspective", "point of view", which "public law" teaching requires to present to the law student. The problem is one of seeing law not only in its direct effects but in terms of its indirect effects on the whole complex society; of sizing up the needs and possible measures and the costs and probable effects, desirable or undesirable, of measures; of reaching for understanding of what our whole organization is for, and not only of what law can do and is doing to help us thither but also of where it is wise to leave the task to other means. 'These are not matters on which two Americans easily agree. Yet we have spoken above of forces driving us toward search for such a view of the whole. Here we suggest that again our tradition of law and teaching indicates the sound road, this time into conduct of such a search. Neither our law nor our general thinking has moved with much success in terms of seizing immediately or early upon a large scale, much less upon a workable, universal principle. The course has been rather one of widening exploration: of exploration, but of exploration in constant quest of a wider basis. The wider view which we require to develop, in the "public" area as in that still felt as largely "private", requires that we keep our feet planted in concrete core-material, but that we go on seeking constaritly to extend both the range of vision and the breadth of the interlocking material to be considered. Nowhere more than in an area clearly shot through with conscious quest for policy does the need for "social science" material appear; nor anywhere does greater need appear to cross existing "borderlines" of legal "fields" and to size up the net effect of larger blocks of law or of government or of life. Yet patience in growth is of the essence of our tradition as much as is unbroken growing.

What we mean by widening the view is not merely, say in learning "administrative procedure" around specialized study of one commission's work that one cast an eye ever and again on variances of practice before other administrative bodies. We mean in addition the search for a steadily widening perspective as a setting for any particular technical area. Thus, somewhere under and somehow common to the more technical rules found in some portions of judicial procedure and the wilder practices found in some portions of administrative procedure there are a body of jobs to be done about the handling of cases of trouble and a body of wisdoms indicated by experience, horse-sense and technically 
informed better-than-ordinary-horse-sense about how fairness and efficiency can be combined. It is quite plain that there are a number of quite different lines of such combination which can, any of them, be reasonably satisfactory in appropriate circumstances. It is for instance plain that some cases in either the judicial or the administrative area will call for summary action, often ex parte; and that the subsequent hearing and due remedy for error which appeals to us so strongly where the summary action is administrative has useful implications in regard to summary judicial action as well. It is plain, again, that along with rules, procedures and review in the judicial field we rely there very heavily indeed on certain largely unspoken traditions of action-in-the-office which we find it very difficult to articulate with any exactitude, but which we feel quite clearly; and that the rules and procedures appropriate to officers of uprightness and intelligence and whose self-restraint within the traditions of the office we trust are not at all the same as the rules and procedures appropriate to officers of a different character. Surely the light which this discrimination sheds on our variant types of judicial procedure is worth using in our canvasses of administrative procedure: not least in uncovering for meditation the degree to which either or any line of procedure may depend for good results on an established and perceptible tradition-of-the-office. And we note here a matter to which we shall be recurring: that the "wider perspective" toward which our problems both technical and "larger" are thrusting us in curricular matters is increasingly taking the form of drawing on that area of general thinking about matters legal which has so long remained neglected as Jurisprudence.

But the fact is that our legal system and our legal scholarship have been curiously backward in general thinking. In particular we have remained deficient in what may be called principles of the third through to the tenth order. Many or most of us have first principles that are clear enough (say: Seek Justice) and even a decent batch of second order principles (say: due process of law); but neither of these is geared in any demonstrable way to the solution of the daily run of our legal problems. In approaching these last our tendency is to work either with more or less authoritative legal principles given us not by first principles but by our going system of legal authorities, or else to turn to the cases and select among them in terms of the historical growth of the particular "field" of law, or else to rest an answer on an honest but somewhat curbstone reaction to the facts and then buttress the answer with available authority lined up to suit that purpose. And most of us feel a consequent discomfort in risking judgments which range outside our 
particular fields-unless those judgments range far enough outside to appear to us as political convictions, in which case few of us either welcome or weigh evidence against them. These things we all know about ourselves, we all smile at them, we indulge them not only in ourselves but, in good American fashion, in our neighbors as well. But the pressures which are forcing "public law" material and thinking upon the curriculum are pressures which require us to modify our ways. The Whole of Our Law does require to be put into intelligible perspective for our students. That great work will be done by no single prophet nor in a few years; nor will it come "naturally" as the mere resultant of political controversy. It calls instead among ourselves and in our classes for a steady widening in any field out beyond the heretofore usual borders; it calls in every field for a bit more of perspective, until we find ourselves making contact and building together.

Let us illustrate briefly from two courses now fairly common, Taxation and Labor Relations. In Taxation it would seem plainly insuffcient to stop with the statute, the regulations, and the decisions. Clientserving skills call for development: how does one do this or that to minimize taxation? The course of tax decisions makes clear that not every supposed landmark contimues to be a landmark: clearly there is a difference between what are roughly speaking current adjustments of a client's affairs and other adjustments whose ultimate incidence and testing will lie far in the future. Per contra, if it would seem insufficient teaching to leave out tax-counsel's job of taking advantage of gaps, it would seem lop-sided teaching to deal with a gap without considering the Treasury's or the legislator's problem of how to close the gap without opening up more trouble than one gets rid of; (and the problem of drafting any solving measure into sound language presents itself as well). Again, surely the question of possible simplification of the taxstructure deserves some sustained study in any taxation-course. Similarly, whether we like it or not and whether or not intentional, taxation has become one of the most important regulative devices in our legal system; its effects in this aspect go to the heart of what we are here calling "perspective".

Such a sampling of familiar themes from a familiar field lays the basis for a suggestion equally obvious but perhaps not quite so familiar: The exclusive bargaining agency under the Labor Relations Acts has certain interesting analogies in regard to the industrial workers concerned, to a party in power after an election in one of our political units. It also has some striking dissimilarities, in that for instance the actual representatives of all are rather the "party-bosses" than any directly 
elected candidates. Such a line of thought is interesting in regard to both the membership provisions and the duration of any collective contract. If an instructor should set about developing lines of this or similar character he would be moving in the direction of what we are speaking of as general perspective.

The three conclusions which seem to us persuasive in regard to "public law" material are therefore: (1) that it can and should be selected and above all taught with primary reference to giving effective training in craft-skills of general application; (2) that it should be selected and above all taught in terms of a steady attempt at widening perspective; (3) that both can be more effectively accomplished by deep and sustained work centered on particular areas and problems of particular administrative bodies than they can by any effort at wider or more inclusive class coverage of informational subject-matter. Again we believe the information and skills developed by returning instructors to point the road. Such men return, we repeat, equipped with specialized knowledge and experience which has a uniquely useful twist. As law teachers, they have sized up their experience with an eye to articulate communication; again as law teachers, they will on their return be reworking and rethinking with an eye to lines of instruction which can make study of the particular yield light on the general. If their fresh knowledge and initiative are put to work before either stales, our profession at large will have promise of developing within a relatively brief period techniques for effective teaching on the still puzzling "public law" side which can hope to rival the effectiveness of classic case-instruction. And it pays to recall again in this connection that the heart of case-instruction ${ }^{17}$ for class purposes is not use of judicial opinions as such but instead of the concrete situation (of which the judicial "case" is but one type), presenting a concrete problem or series of problems, with the class really grasping the background and the problems, being trained in solution by actually trying to solve until solving becomes a thing each member of the class knows how to do, and moreover does by trained habit.

Even if "public law" instruction had had opportunity to "shake down" by now into a series of standard offerings, methods, and gross time-allotments as "normal" as the old-line case-courses, the fresh possibilities opened by the prospective returning instructors and the quite unforeseeable range of new "public law" fields-State as well as Federal -would make it inappropriate for this report to suggest any particular material as desirable, or any particular proportion of total curricular

17. But see note 8 , supra.-D. F. Cavers. 
time. We see both matters as likely to undergo wide variation not only as among the faculties, but even within any faculty.

We do remind, however, that many "new" case-courses and many new case-books and styles of case-book were tried and modified in the exciting years when case-instruction was conquering the country, before we arrived at such standardization as we now have in case-instruction. Consider the "Summary" which once was a necessary part of the casebook; or Ames's defunct case-books on Bills and Notes or Pleading; or Municipal Corporations as a subject; or what has happened to Kales' effort on Restraint of Trade or Beale's on Legal Liability. We'remind also that despite the existence of a recognizable something called "casemethod", the variances are still-or have again become-many and far reaching, and that even individual instructors change their version of that method through the years. In Corbin's last teaching years, for instance, he introduced and found very good a daily brief true-false paper to police the case-rcading and to focus the ensuing class-discussion. We have no business to expect any teaching which reaches at all for new and needed "retooling" of method to spring into clean-running existence with no "bugs" to be ironed out. We have every reason to expect that during the bug-ironing period an instructor's enthusiasm will carry his class. We have, above all, to remember our sadly recurring blue-books with their sadly recurring evidence that except for the more gifted students all is far from well. We can also in that connection recall again the course of class-instruction, slowed up and slowed up again from the second semester onward by some failure of a technique we had assumed to be on tap and habitual throughout the class-and we can profitably wonder whether more sustained concentration on craft-techniques may not lift our pack-pace and give us more of what we as teachers most thirst for: effective class-time.

Save for Constitutional Law, which can be regarded as now "established" in the curriculum, and Taxation, we have ventured no suggestion in regard to specific desirable material. We do point out that the "public law" area opens up, as possible lines of training, a considerable body of skills we have not discussed. We mention here only two. The first is the drafting of regulations or of statutes, as contrasted with "writing" as applied to pleadings, briefs or documents to cover particular transactions. ("Collective" contracts designed to serve as a sort of private statute for a trade-group or a labor unit for a period partake of both these types of drafting.) The second is the technique of going about making an intelligent policy decision, whether it be in a small matter or in a large. 
We call attention also to the fact that the problem of providing orientation information, presses in the "public law" field if possible even more than in the private. We see no way out, in either area, by way of intensive class-instruction. We suspect that to this end also books-for law students require to be written and to be used in conjunction with syllabus, lecture-courses, and possible occasional quiz or question sessions.

Finally, we risk the suggestion that it will pay any faculty to consider the possibility of introducing a course which seeks to sum up something of the meaning and working of our legal system as a whole. It is very dubious how much this needed job can gain from a review of the legal philosophers of the past. Few of them have had their minds at work on a legal system remotely similar to ours. But what our system comes to, and the part played and proper to be played by law in our society and by the lawyer in relation to both law and society, and the relation of all of this to the ideals around which our society is and must remain organized - these are things almost impossible as yet to find in books, and things which we nevertheless owe it to our students to make accessible: if not by way of books, then by way of a course. The job any one of us can do along this line between this year and next-or any dozen of us-will be a pretty disappointing job; let that be granted. But what can come out of ten years of work, begun now by many of usthat holds a different kind of promise. Meanwhile, shall the graduate go out with empty hands?

\section{0. "Professional" and "Untversity" Character of the Sugges- TIONS.}

Before closing we have one defense to make against an hypothetical objection. As university law schools, we have in the past been concerned, and rightly concerned, to make our training not a "trade" training but a training for a profession. We have striven away from mere tricks of the trade, we have striven into deeper theory. As university law schools, moreover, we have been concerned to impart a discipline upon a university level, a discipline which in integrity of subject matter and clean rigor of thinking could hold its head high among the other disciplines of the campus.

We submit that the suggestions made in this report not only are in consonance with this but represent a definite machinery for advancing both these professional ideals and these university ideals, and for enriching them. On the side of rigor of thinking your Committee have begun with the need for recapturing, throughout the student body, the 
rigor of the classic case-instruction. On the side of statutory construction, drafting and appellate argument what is urged is the conscious development, on the legal side, not only of craft-skills but of that use of art in language which is a major phase of the humanities-not alongside legal work, but within it. The brief is indeed a special genre of literature, and a lovely one, barred only by its technical content from study and appreciation by our neighbors in the Department of Literature. And it pays lawyers to remember that if it was on the terse beauty of the Code Napoleon that Stendhal learned literary style, a contract or a pleading can be made to show such beauty with nothing but gain in effectiveness. So far as concerns the "human-nature" phases of counselling, advocacy or other skills of practice, they rest either in that wisdom which is the goal of all university work or else in a field called psychology which our brethren accept as one of ample university stature. So far finally as we have dealt with "public" phases of the law, the material itself and our suggestions run both in terms of the very function of a university: a view of any discipline in terms of its meaning to the whole.

But if there be one school in a university of which it should be said that there men learn to give practieal reality, practical effectiveness, to vision and to ideals, that school is the school of law. Our suggestion is that, rightly approached, the road to sure vision proves to be at the same time the road to true command of skill in practice: that that lesson from classic class-instruction is what needs relearning and reapplication in the light of current conditions.

Respectfully submitted,

Charles Bunn, University of Wisconsin

David F. Cavers, Duke University

JUDSON F. FALKNOR, University of Washington

Lester W. Feezer, University of Arizona

Frederick J. Moreau, University of Kansas

Kard N. LiEWellyn, Columbia University, Chairman 